\title{
Correction to: Bilateral Radial Head Fracture Secondary to Weighted Push-Up Exercise: Case Report and Review of Literature of a Rare Injury
}

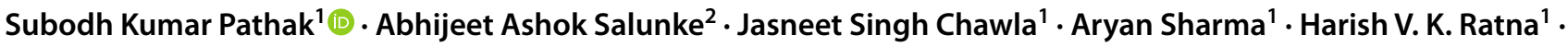 \\ Rakesh Kumar Gautam ${ }^{1}$
}

Published online: 18 June 2021

(c) Indian Orthopaedics Association 2021

\section{Correction to: Indian Journal of Orthopaedics https://doi.org/10.1007/s43465-021-00427-0}

The original version of this article unfortunately contained a mistake. The corresponding author was incorrectly assigned. The correct corresponding author is Subodh Kumar Pathak.

The original article has been corrected.

Publisher's Note Springer Nature remains neutral with regard to jurisdictional claims in published maps and institutional affiliations.

The original article can be found online at https://doi.org/10.1007/ s43465-021-00427-0.

Subodh Kumar Pathak

drsubodh08@gmail.com

Abhijeet Ashok Salunke

drabhijeetsalunke@gmail.com

Jasneet Singh Chawla

jasneetchawla@ymail.com

Aryan Sharma

aryansharma9999@gmail.com

Harish V. K. Ratna

harivk07@gmail.com

Rakesh Kumar Gautam

ortho1415@gmail.com

1 Department of Orthopaedics, Maharishi Markandeshwar Institute of Medical Sciences and Research, MM (Deemed to be University), Ambala, India

2 Gujarat Cancer and Research Institute, Ahmedabad, Gujarat, India 